\title{
Reversible renal-limited thrombotic microangiopathy due to gemcitabine- dexamethasone-cisplatin therapy: a case report
}

Masashi Nishikubo ${ }^{1 *}$ (D), Yoshimitsu Shimomura ${ }^{1}$, Nobuhiro Hiramoto ${ }^{1}$, Naohiko Sawamura ${ }^{2}$, Takako Yamaguchi ${ }^{3}$, Shigeo Hara $^{3}$ and Takayuki Ishikawa ${ }^{1}$

\begin{abstract}
Background: Gemcitabine and cisplatin are chemotherapeutic agents used for treating multiple cancers, and these agents are sometimes used in combination. Drug-induced thrombotic microangiopathy (TMA) is a rare but potentially fatal complication. It typically presents as a systemic disease with the classical triad of hemolytic anemia, thrombocytopenia, and organ damage. In contrast to systemic TMA, cases of renal-limited TMA, defined as biopsyproven renal TMA without the classical triad, have been reported with relatively good prognosis. Most cases of renal-limited TMA are associated with calcineurin inhibitors, and cases of drug-induced renal-limited TMA due to gemcitabine-dexamethasone-cisplatin therapy have been rarely reported.

Case presentation: A 43-year-old woman with lymphoma developed acute kidney injury with marked proteinuria, microhematuria, and abnormal urinary casts after receiving one cycle of gemcitabine-dexamethasone-cisplatin therapy. Although she did not show hemolytic anemia and thrombocytopenia, renal biopsy showed diffuse injury to the glomerular endothelial cells, supporting the diagnosis of renal-limited TMA. Her condition improved only with the cessation of gemcitabine and cisplatin treatment. She received another chemotherapy without gemcitabine and platinum agents, and no recurrence of renal-limited TMA was observed.

Conclusions: Drug-induced TMA occurs early after gemcitabine and cisplatin use in renal-limited form and is reversible when detected and managed in a timely manner. Urinalysis, which is simple and inexpensive and can be easily performed, is a beneficial screening tool for early-onset drug-induced TMA among patients who receive gemcitabine-dexamethasone-cisplatin therapy.
\end{abstract}

Keywords: Thrombotic microangiopathies, Gemcitabine, Cisplatin, Urinalysis, Lymphoma, Proteinuria

\footnotetext{
* Correspondence: mnishi90@yahoo.co.jp

'Department of Hematology, Kobe City Medical Center General Hospital, 2-1-1 Minami-machi, Minatojima, Chuo-ku, Kobe, Hyogo 650-0047, Japan Full list of author information is available at the end of the article
}

(c) The Author(s). 2021 Open Access This article is licensed under a Creative Commons Attribution 4.0 International License, which permits use, sharing, adaptation, distribution and reproduction in any medium or format, as long as you give appropriate credit to the original author(s) and the source, provide a link to the Creative Commons licence, and indicate if changes were made. The images or other third party material in this article are included in the article's Creative Commons. licence, unless indicated otherwise in a credit line to the material. If material is not included in the article's Creative Commons licence and your intended use is not permitted by statutory regulation or exceeds the permitted use, you will need to obtain permission directly from the copyright holder. To view a copy of this licence, visit http://creativecommons.org/licenses/by/4.0/ The Creative Commons Public Domain Dedication waiver (http://creativecommons.org/publicdomain/zero/1.0/) applies to the data made available in this article, unless otherwise stated in a credit line to the data. 


\section{Background}

Drug-induced thrombotic microangiopathy (TMA) is a rare but significant complication associated with multiple drugs, including chemotherapeutic agents [1]. Gemcitabine, a deoxycytidine analog, and cisplatin, a platinum-containing agent, are widely used as chemotherapeutic agents for malignancy. The combination of gemcitabine and cisplatin is employed in some cases, such as non-small-cell lung carcinoma; hepatobiliary, pancreatic, and urothelial cancer; and relapsed or refractory non-Hodgkin lymphoma [2-7]. Both gemcitabine and cisplatin have been reported to cause drug-induced TMA [8-11]. Regarding drug-induced TMA due to gemcitabine, its incidence has been reported to range from 0.015 to $1.4 \%$ [12]. The risk increases with the dose of gemcitabine and with prolonged duration of treatment [12]. Similarly, drug-induced TMA due to cisplatin has been also reported, although it is significantly less frequent than gemcitabine [9, 13]. Drug-induced TMA is a severe complication associated with significant mortality regardless of causative agents [10, 12, 13], and renal damage possibly leading to end-stage renal disease is one of complications observed in drug-induced TMA [12]. Clinically, this condition manifests as a systemic disease, with the classical triad of hemolytic anemia, thrombocytopenia, and organ damage, including renal insufficiency [12, 13]. Apart from the systemic form of TMA, few cases of drug-induced TMA due to gemcitabine and cisplatin, localized in the kidneys, have been reported. Herein, we report a case of a 43-year-old woman with drug-induced renal-limited TMA, which developed after one cycle of gemcitabine-dexamethasone-cisplatin (GDP) therapy. Her condition improved rapidly after cessation of GDP therapy, and urinalysis was beneficial for the early detection of drug-induced TMA.

\section{Case presentation}

A 43-year-old Japanese woman was admitted to our hospital for the treatment of angioimmunoblastic T-cell lymphoma. She presented with continuous high fever and a disseminated skin rash. Laboratory data showed elevated lactate dehydrogenase ( $\mathrm{LDH}), \mathrm{C}$-reactive protein (CRP), and soluble-interleukin-2 receptor levels at hospitalization. She received two cycles of cyclophosphamide, vincristine, doxorubicin, and prednisolone (CHOP) therapy. Her symptoms and abnormal laboratory findings were temporally resolved with chemotherapy initiation, but these worsened after the neutrophil recovery in each course. Positron emission tomography demonstrated residual uptake of fluorodeoxyglucose in the spleen and iliac lymph nodes, suggesting the ineffectiveness of CHOP therapy. Subsequently, she received GDP therapy, which consisted of $1000 \mathrm{mg} / \mathrm{m}^{2}$ of gemcitabine on days 1 and $8,33 \mathrm{mg} /$ day of dexamethasone from day 1 to day 4 , and $75 \mathrm{mg} / \mathrm{m}^{2}$ of cisplatin on day 1 [14]. She received one cycle of GDP therapy as scheduled above with $2800 \mathrm{mg}$ of gemcitabine and $100 \mathrm{mg}$ of cisplatin in total. She developed acute kidney injury $(\mathrm{AKI})$ with a creatinine $(\mathrm{Cr})$ level of $0.35 \mathrm{mg} / \mathrm{dL}$ to $0.77 \mathrm{mg} / \mathrm{dL}$, proteinuria $(402 \mathrm{mg} / \mathrm{gCr}$ ), and microhematuria (1-4/high-power field of red blood cell without dysmorphic change) 9 days after the initiation of GDP therapy. Her AKI failed to improve despite hydration and worsened 21 days after the initiation of GDP therapy. Her physical examination at this time revealed a blood pressure of $118 / 58 \mathrm{mmHg}$, and the other vital signs were unremarkable. Laboratory findings showed anemia without signs of hemolysis and thrombocytosis and elevated liver enzyme, LDH, and CRP levels (Table 1). There were no coagulopathy and schistocytes in the peripheral blood smear. The abnormal findings of liver enzymes, LDH, and CRP were similar to the previous deteriorations observed after neutrophil recovery of each $\mathrm{CHOP}$ therapy and were considered to be mainly due to refractory lymphoma. Regarding the elevated LDH level, based on the absence of findings suggesting hemolysis, such as progressive anemia, elevated indirect bilirubin level, and presence of schistocytes in the peripheral blood smear, it suggested systemic inflammation, not hemolysis. Urinalysis showed marked proteinuria $(6549 \mathrm{mg} / \mathrm{gCr})$, microhematuria (30-49/highpower field of red blood cell with dysmorphic change), and hyaline, granular, waxy, and epithelial casts. A 24-h urine specimen showed a protein level of $2464 \mathrm{mg} /$ day. Next, we cancelled the scheduled second GDP therapy and performed a renal biopsy. Moreover, histological findings revealed diffuse and global endothelial swelling, double contours of the glomerular basement membranes, and scattered foamy macrophages. Electron microscopic findings revealed subendothelial edema and new basement membrane formation (Fig. 1). Immune complexes were not found on immunofluorescence. Immunofluorescence staining of complement $\mathrm{C} 3$ and $\mathrm{C} 4$ was negative. Based on the history of chemotherapy and the absence of the classical triad of systemic TMA, such as hemolytic anemia, thrombocytopenia, and organ damage other than the kidneys, the patient was diagnosed with drug-induced renallimited TMA due to GDP therapy. She was followed up carefully, and her proteinuria improved gradually. Her AKI also improved to baseline with a Cr level of $0.43 \mathrm{mg} /$ $\mathrm{dL}$ and proteinuria of less than $500 \mathrm{mg} / \mathrm{gCr} 36$ days after the initiation of GDP therapy. She received another chemotherapy without gemcitabine and platinating agents, and no recurrence of renal-limited TMA was observed (Fig. 2).

\section{Discussion and conclusions}

The clinical course of this patient raised two critical issues. First, few doses of gemcitabine and cisplatin can cause renal-limited TMA. Second, renal-limited TMA 
Table 1 Laboratory findings at renal-limited thrombotic microangiopathy onset

\begin{tabular}{|c|c|c|}
\hline Test & Result & Reference range \\
\hline WBC (white blood cells) $(/ \mu \mathrm{L})$ & 7600 & $3900-9800$ \\
\hline Hemoglobin (g/dL) & 9.0 & $11.1-15.1$ \\
\hline PLT (platelet count) $\times 10^{4} / \mu \mathrm{L}$ & 51.4 & $13.0-37.0$ \\
\hline TP (total protein (g/dL) & 5.9 & $6.5-8.5$ \\
\hline Albumin (g/dL) & 3.2 & $3.9-4.9$ \\
\hline T-Bil (total-bilirubin) (mg/dL) & 0.7 & $0.2-1.2$ \\
\hline AST (aspartate aminotransferase) (U/L) & 42 & $8-40$ \\
\hline ALT (alanine aminotransferase) (U/L) & 131 & $8-40$ \\
\hline LDH (lactate dehydrogenase) (U/L) & 573 & $124-222$ \\
\hline Urea (mg/dL) & 19.2 & $8.0-20.0$ \\
\hline Creatinine (mg/dL) & 0.78 & $0.40-0.80$ \\
\hline CRP (C-reactive protein) (mg/dL) & 10.36 & $0.00-0.50$ \\
\hline PT-INR (prothrombin time-international normalized ratio) & 1.10 & \\
\hline APTT (activated partial thromboplastin time (sec) & 26.9 & $24.3-38.9$ \\
\hline Fibrinogen (mg/dL) & 483 & $180-320$ \\
\hline Complement C3 (mg/dL) & 103 & $65-135$ \\
\hline Complement C4 (mg/dL) & 31 & $13-35$ \\
\hline
\end{tabular}

due to GDP therapy can be alleviated by treatment cessation, and urinalysis may be useful for early detection.

TMA is a pathologic disease entity characterized by generalized microvascular occlusion by platelet emboli, triggered by multiple etiologies, including medications [15]. It presents with the classical triad of thrombocytopenia, microangiopathic hemolytic anemia, and organ injury, including AKI. Apart from the systemic form of TMA, renal-limited TMA cases, defined as biopsy-proven renal TMA without the classical triad, have been reported [13]. Most renal-limited TMA cases are associated with calcineurin inhibitors, which are used for immunosuppression after kidney transplantation [16, 17]. Bevacizumab and quinine can also cause renallimited TMA [18, 19]. In contrast, although both gemcitabine and cisplatin have been reported as causative agents of drug-induced systemic TMA, alone or in combination, few cases of renal-limited drug-induced TMA with those agents have been reported [16].

The primary side effects of GDP therapy are myelosuppression, mild liver function abnormalities, gastrointestinal symptoms, infection, thrombosis or embolism, and edema [6, 7]. Regarding gemcitabine, mild proteinuria and hematuria have been commonly reported as side effects of gemcitabine, but these are rarely clinically significant [20]. Although rare, drug-induced TMA due to gemcitabine is a severe complication [12], and the risk of systemic TMA is more significant when the cumulative dose exceeds $12,000 \mathrm{mg} / \mathrm{m}^{2}$ or when the treatment lasts longer than 7 months [12, 21]. However, lower

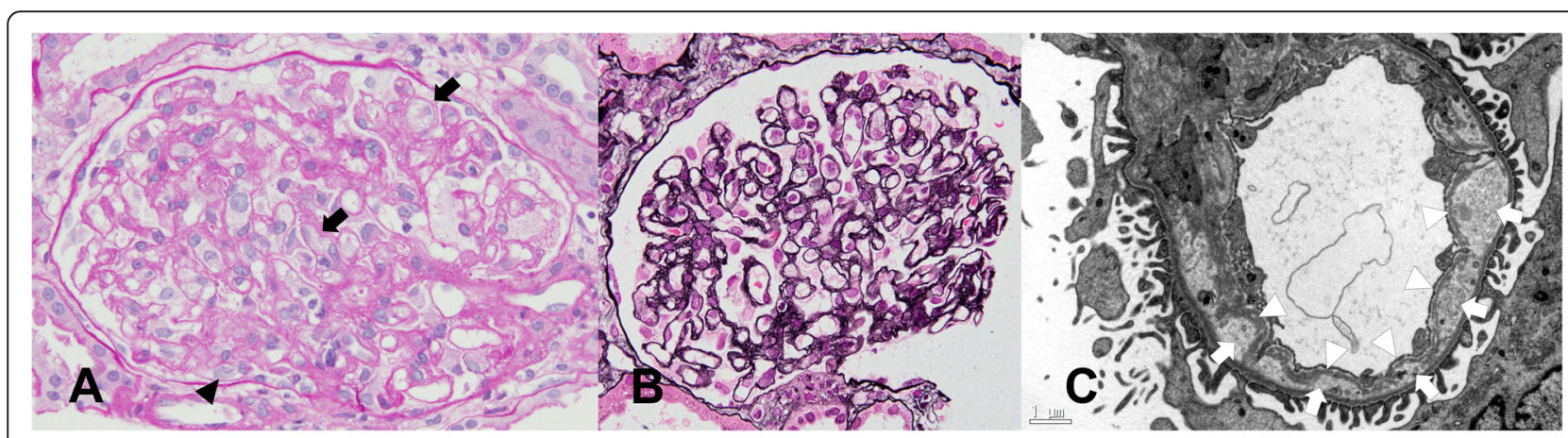

Fig. 1 Renal biopsy finding. a Periodic acid-Schiff staining $(\times 400)$. The glomerulus shows diffuse endothelial swelling (a black arrowhead) and scattered foamy macrophages (black arrows). b Periodic acid-methenamine silver staining ( $\times 400)$. Reduplication of the glomerular basement membrane is observed. c Electron micrograph of a glomerular basement membrane ( $\times 6000)$. New basement membrane formation (white arrowheads) and subendothelial edema (white arrows) are present 


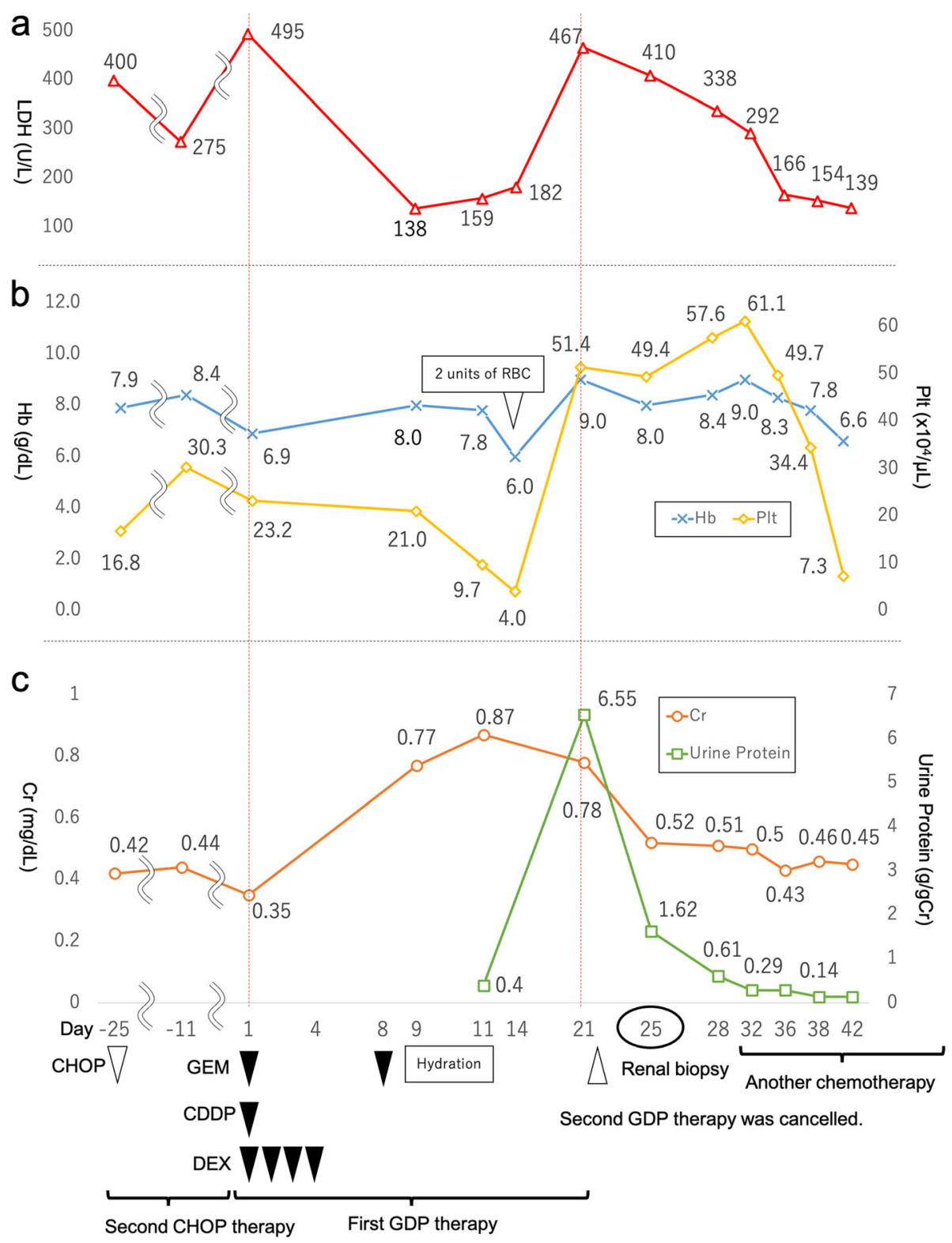

Fig. 2 Her clinical course. Day 1 stands for the day when the first dose of gemcitabine-dexamethasone-cisplatin therapy was administered. a LDH levels. The elevation of LDH was observed at the beginning of each chemotherapy. It temporally resolved with chemotherapy initiation, but it worsened after the neutrophil recovery in each course. At the onset of renal-limited TMA, it was observed again probably due to lymphoma itself and inflammation with TMA. It gradually improved with the cessation of GDP therapy and got normalized after the administration of another chemotherapy. $\mathbf{b}$ Hemoglobin and platelet levels. The patient already had anemia due to chronic inflammation of refractory lymphoma and myelosuppression due to chemotherapy. However, at the onset of renal-limited TMA, her anemia did not deteriorate; rather, it improved. Also, at the onset of renal-limited TMA, thrombocytosis, not thrombocytopenia, was observed. c Creatinine levels, the amount of urine protein and interventions. The doses of chemotherapy were as follows: $1000 \mathrm{mg} / \mathrm{m}^{2}$ of gemcitabine on days 1 and $8,33 \mathrm{mg} /$ day of dexamethasone from day 1 to day 4 , and $75 \mathrm{mg} / \mathrm{m}^{2}$ of cisplatin on day 1 . Abbreviations. GEM: gemcitabine. CDDP: cisplatin. DEX: dexamethasone. RBC: red blood cells

doses of gemcitabine with or without other anticancer drugs including cisplatin can be the cause of systemic TMA [10, 22, 23]. In the present case report, renallimited TMA developed after the patient was exposed to only $2000 \mathrm{mg} / \mathrm{m}^{2}$ of gemcitabine and $75 \mathrm{mg} / \mathrm{m}^{2}$ of cisplatin, although it is not clear to what extent each drug contributed to the development of TMA. Therefore, clinicians should consider TMA in cases with findings suggestive of TMA, including proteinuria, among patients receiving gemcitabine and cisplatin, even when the cumulative dose is not significant.

Renal-limited TMA usually presents with proteinuria or AKI, and in cases of renal transplant patients, it can be suspected with delayed graft function [16]. 
Minimization or temporary withdrawal of causative medications is the major therapeutic intervention, and the prognosis is relatively good, with the survival ranging from 75 to $100 \%$ [17, 24, 25]. However, once systemic drug-induced TMA associated with gemcitabine and/or cisplatin has developed, treatment cessation alone is rarely curative $[12,13]$. Intensive treatment plans, such as plasma exchange, fresh frozen plasma infusion, and steroids and eculizumab administration, are indicated. Although it is still controversial, renal-limited TMA may be a prodromal stage of systemic TMA. Cases wherein TMA initially localizes to the kidney on biopsy, but subsequently progresses to manifest as systemic TMA, have been reported $[26,27]$. Therefore, early recognition and prompt intervention are warranted. In the present case report, we detected renal-limited drug-induced TMA by urinalysis. Early detection prompted treatment cessation, which resulted in complete improvement of symptoms. Since urinalysis is simple, inexpensive, and easily performed, routine urinalysis may be useful for early detection and intervention with chemotherapy modification. There are some limitations in our case report. Unfortunately, we did not investigate the Coombs test, haptoglobin value, and ADAMTS- 13 activity because we did not consider TMA as a differential diagnosis at the onset of TMA. We did not also perform the genetic analysis of complement genes, which is not available on a commercial basis in Japan.

In conclusion, GDP therapy caused renal-limited TMA, even when the cumulative dose of gemcitabine or cisplatin was low. With early detection and prompt cessation of causative agents, it was still reversible. Routine screening with urinalysis may be beneficial for patients receiving GDP therapy.

\section{Abbreviations}

TMA: Thrombotic microangiopathy; CHOP: Cyclophosphamide, vincristine, doxorubicin, and prednisolone; GDP: Gemcitabine, dexamethasone, and cisplatin; AKI: Acute kidney injury; Cr: Creatinine

\section{Acknowledgments}

None.

\section{Authors' contributions}

MN collected the data and wrote the first draft of the manuscript. NS, TY, and $\mathrm{SH}$ provided pathological information and comments. YS supervised the manuscript writing, editing, and review. $\mathrm{NH}$ and $\mathrm{TI}$ coordinated the project and edited the manuscript. All authors read and approved the final manuscript.

\section{Funding}

None.

Availability of data and materials

Not applicable.

\section{Declarations}

Ethics approval and consent to participate Not applicable.

\section{Consent for publication}

Written informed consent was obtained from the patient for publication of this case report and any accompanying images. A copy of the written consent is available for review by the editor of this journal.

\section{Competing interests}

The authors declare that they have no competing interests.

\section{Author details}

'Department of Hematology, Kobe City Medical Center General Hospital, 2-1-1 Minami-machi, Minatojima, Chuo-ku, Kobe, Hyogo 650-0047, Japan. ${ }^{2}$ Department of Nephrology, Kobe City Medical Center General Hospital, Kobe, Hyogo 650-0047, Japan. ${ }^{3}$ Department of Pathology, Kobe City Medical Center General Hospital, Kobe, Hyogo 650-0047, Japan.

Received: 10 March 2021 Accepted: 4 May 2021

Published online: 12 May 2021

\section{References}

1. Al-Nouri ZL, Reese JA, Terrell DR, Vesely SK, George JN. Drug-induced thrombotic microangiopathy: a systematic review of published reports. Blood. 2015;125(4):616-8. https://doi.org/10.1182/blood-2014-11-611335.

2. Scagliotti GV, Parikh P, von Pawel J, Biesma B, Vansteenkiste J, Manegold C, et al. Phase III study comparing cisplatin plus gemcitabine with cisplatin plus pemetrexed in chemotherapy-naive patients with advanced-stage nonsmall-cell lung cancer. J Clin Oncol. 2008;26(21):3543-51. https://doi.org/1 0.1200/JCO.2007.15.0375

3. Valle J, Wasan H, Palmer DH, Cunningham D, Anthoney A, Maraveyas A, et al. Cisplatin plus gemcitabine versus gemcitabine for biliary tract cancer. N Engl J Med. 2010;362(14):1273-81. https://doi.org/10.1056/NEJMoa 0908721.

4. Heinemann V, Quietzsch D, Gieseler F, Gonnermann M, Schönekäs H, Rost A, et al. Randomized phase III trial of gemcitabine plus cisplatin compared with gemcitabine alone in advanced pancreatic cancer. J Clin Oncol. 2006; 24(24):3946-52. https://doi.org/10.1200/JCO.2005.05.1490.

5. Bellmunt J, von der Maase H, Mead GM, Skoneczna I, De Santis M, Daugaard G, et al. Randomized phase III study comparing paclitaxel/ cisplatin/gemcitabine and gemcitabine/cisplatin in patients with locally advanced or metastatic urothelial cancer without prior systemic therapy: EORTC intergroup study 30987. J Clin Oncol. 2012;30(10):1107-13. https:// doi.org/10.1200/JCO.2011.38.6979.

6. Crump M, Baetz T, Couban S, Belch A, Marcellus D, Howson-Jan K, et al. Gemcitabine, dexamethasone, and cisplatin in patients with recurrent or refractory aggressive histology B-cell non-Hodgkin lymphoma: a phase II study by the National Cancer Institute of Canada clinical trials group (NCICCTG). Cancer. 2004;101(8):1835-42. https://doi.org/10.1002/cncr.20587.

7. Crump M, Kuruvilla J, Couban S, MacDonald DA, Kukreti V, Kouroukis CT, et al. Randomized comparison of gemcitabine, dexamethasone, and cisplatin versus dexamethasone, cytarabine, and cisplatin chemotherapy before autologous stem-cell transplantation for relapsed and refractory aggressive Iymphomas: NCIC-CTG LY.12. J Clin Oncol. 2014;32(31):3490-6. https://doi.org/10.1200/JCO.2013.53.9593.

8. Rabinowits G, Herchenhorn D, Rabinowits M, Weatge D, Torres W. Fatal pulmonary toxicity in a patient treated with gefitinib for non-small cell lung cancer after previous hemolytic-uremic syndrome due to gemcitabine. AntiCancer Drugs. 2003;14(8):665-8. https://doi.org/10.1097/00001813-2003 09000-00014.

9. Gilbert RD, Stanley LK, Fowler DJ, Angus EM, Hardy SA, Goodship TH. Cisplatin-induced haemolytic uraemic syndrome associated with a novel intronic mutation of CD46 treated with eculizumab. Clin Kidney J. 2013;6(4): 421-5. https://doi.org/10.1093/ckj/sft065.

10. Zupancic M, Shah PC, Shah-Khan F. Gemcitabine-associated thrombotic thrombocytopenic purpura. Lancet Oncol. 2007;8(7):634-41. https://doi. org/10.1016/S1470-2045(07)70203-6.

11. Manohar S, Leung N. Cisplatin nephrotoxicity: a review of the literature. J Nephrol. 2018;31(1):15-25. https://doi.org/10.1007/s40620-017-0392-z.

12. Daviet F, Rouby F, Poullin P, Moussi-Francès J, Sallée M, Burtey S, et al. Thrombotic microangiopathy associated with gemcitabine use: presentation and outcome in a national French retrospective cohort. Br J Clin Pharmacol. 2019;85(2):403-12. https://doi.org/10.1111/bcp.13808. 
13. van der Heijden M, Ackland SP, Deveridge S. Haemolytic uraemic syndrome associated with bleomycin, epirubicin and cisplatin chemotherapy-a case report and review of the literature. Acta Oncol. 1998;37(1):107-9. https://doi. org/10.1080/028418698423267.

14. Morschhauser F, Depil S, Jourdan E, Wetterwald M, Bouabdallah R, Marit G, et al. Phase II study of gemcitabine-dexamethasone with or without cisplatin in relapsed or refractory mantle cell lymphoma. Ann Oncol. 2007; 18(2):370-5. https://doi.org/10.1093/annonc/mdl395.

15. Brocklebank V, Wood KM, Kavanagh D. Thrombotic microangiopathy and the kidney. Clin J Am Soc Nephrol. 2018;13(2):300-17. https://doi.org/10.221 5/CJN.00620117.

16. Schwimmer J, Nadasdy TA, Spitalnik PF, Kaplan KL, Zand MS. De novo thrombotic microangiopathy in renal transplant recipients: a comparison of hemolytic uremic syndrome with localized renal thrombotic microangiopathy. Am J Kidney Dis. 2003;41(2):471-9. https://doi.org/10.1 053/ajkd.2003.50058

17. Zarifian A, Meleg-Smith S, O'donovan R, Tesi RJ, Batuman V. Cyclosporineassociated thrombotic microangiopathy in renal allografts. Kidney Int. 1999; 55(6):2457-66. https://doi.org/10.1046/j.1523-1755.1999.00492.x.

18. Yamada R, Okawa T, Matsuo K, Suzuki M, Mori N, Mori K. Renal-limited thrombotic microangiopathy after switching from bevacizumab to ramucirumab: a case report. BMC Nephrol. 2019;20(1):14. https://doi.org/1 0.1186/s12882-018-1194-9.

19. Anjelo J, Rao N, David VG, Otto S, Russ G. Renal-limited thrombotic microangiopathy and acute interstitial nephritis with a single dose of quinine. Clin Kidney J. 2014;7(3):311-3. https://doi.org/10.1093/ckj/sfu035.

20. Aapro MS, Martin C, Hatty S. Gemcitabine--a safety review. Anti-Cancer Drugs. 1998;9(3):191-201. https://doi.org/10.1097/00001813-19980300000001.

21. Saif MW, Xyla V, Makrilia N, Bliziotis I, Syrigos K. Thrombotic microangiopathy associated with gemcitabine: rare but real. Expert Opin Drug Saf. 2009;8(3):257-60. https://doi.org/10.1517/14740330902942299.

22. De Smet D, Jochmans K, Neyns B. Development of thrombotic thrombocytopenic purpura after a single dose of gemcitabine. Ann Hematol. 2008;87(6):495-6. https://doi.org/10.1007/s00277-007-0429-9.

23. Willemsen $A E$, van Herpen $C M$, Wesseling $P$, Bult $P$, van Laarhoven HW. Fatal thrombotic microangiopathy after a single dose of gemcitabine as fourthline palliative treatment for metastasized ductal breast carcinoma. Acta Oncol. 2011;50(3):462-5. https://doi.org/10.3109/0284186X.2010.491088.

24. Young BA, Marsh CL, Alpers CE, Davis CL. Cyclosporine-associated thrombotic microangiopathy/hemolytic uremic syndrome following kidney and kidney-pancreas transplantation. Am J Kidney Dis. 1996;28(4):561-71. https://doi.org/10.1016/S0272-6386(96)90468-0.

25. Hochstetler LA, Flanigan MJ, Lager DJ. Transplant-associated thrombotic microangiopathy: the role of $\lg \mathrm{G}$ administration as initial therapy. Am J Kidney Dis. 1994:23(3):444-50. https://doi.org/10.1016/S0272-6386(12)810109

26. Pham PT, Peng A, Wilkinson AH, Gritsch HA, Lassman C, Pham PC, et al. Cyclosporine and tacrolimus-associated thrombotic microangiopathy. Am J Kidney Dis. 2000;36(4):844-50. https://doi.org/10.1053/ajkd.2000.17690.

27. Trimarchi HM, Truong LD, Brennan S, Gonzalez JM, Suki WN. FK506associated thrombotic microangiopathy: report of two cases and review of the literature. Transplantation. 1999;67(4):539-44. https://doi.org/10.1097/ 00007890-199902270-00009.

\section{Publisher's Note}

Springer Nature remains neutral with regard to jurisdictional claims in published maps and institutional affiliations.

Ready to submit your research? Choose BMC and benefit from:

- fast, convenient online submission

- thorough peer review by experienced researchers in your field

- rapid publication on acceptance

- support for research data, including large and complex data types

- gold Open Access which fosters wider collaboration and increased citations

- maximum visibility for your research: over $100 \mathrm{M}$ website views per year

At $\mathrm{BMC}$, research is always in progress.

Learn more biomedcentral.com/submissions 